\title{
NANOTECNOLOGIA E A VULNERABILIDADE DOS TRABALHADORES EM SEU AMBIENTE LABORATIVO: OS DESAFIOS GERADOS PELA IN (EXISTENCIA) DE NORMAS PROTETIVAS TRABALHISTAS
}

\author{
Claudino Gomes* \\ Wilson Engelmann**
}

RESUMO: O estudo tem como objetivo principal destacar a necessidade de regulamentações próprias para proteção dos trabalhadores, frente ao uso de nanotecnologias no ambiente de trabalho, o que os tornam vulneráveis. Como objetivos específicos, busca-se apontar os aspectos de segurança eficazes na manipulação em contato com nanocompósitos, apontar ações que contribuam no meio ambiente de trabalho para torná-lo mais seguro, em respeito a dignidade do trabalhador. Metodologicamente a pesquisa será bibliográfica, comparativa com a legislação celetista existente, pretendem-se apontar, os riscos destes trabalhadores que manipulam ou estão em contato com nanocompósitos, trazendo um novo modo de pensar o Direito do Trabalho.

Palavras-Chave: Nanotecnologia; Direito do Trabalho; Vulnerável; Normas; Proteção.

\section{NANOTECHNOLOGY AND THE VULNERABILITY OF WORKERS IN THEIR LABORATORY ENVIRONMENT: THE CHALLENGES GENERATED BY THE (IN EXISTENCE) OF PROTECTIVE LABOR STANDARDS}

\begin{abstract}
The main objective this study is to highlight the need for specific regulations to protect workers against the use of nanotechnologies in the workplace, which make them vulnerable. Specific objectives it's sought to point out the effective safety aspects in the handling contact with nanocomposites, to point out actions that contribute in the working environment to make it safer, in respect the dignity of the worker. Methodologically, the research will be bibliographical, comparative with existing legislation, to point out the risks, of these workers who manipulate or are in contact with nanocomposites, bringing new way of thinking about Right Work.
\end{abstract}

Keywords: Nanotechnology; Right Work; Vulnerable; Standards; Protection.

*Professor Direito e Processo do Trabalho na UNIRV - Rio Verde - GO, Doutorando em Direito na UNICEUB/Brasília-DF, Mestre em Direito - PUC/GO, Especialista em Direito e Processo do Trabalho pela FASAM/GO; pesquisador da FAPEG. E-mail: claudinog@gmail.com.

${ }^{* *}$ Professor. Dr. Wilson Engelmann, Coordenador Executivo do Mestrado Profissional em Direito da Empresa e dos Negócios da UNISINOS; Professor e Pesquisador do Programa de Pós Graduação em Direito - Mestrado e Doutorado - da UNISINOS; Bolsista de Produtividade em Pesquisa do CNPq. E-mail: wengelmann@unisinos.br.

Rev. de Direitos Fundamentais nas Relações do Trabalho, Sociais e Empresariais | e-ISSN: 2525-9903 | Porto Alegre | v. 4 | 


\section{1 - INTRODUÇÃO}

As nanotecnologias ${ }^{1}$ vêm revolucionando uma série de setores como as áreas da medicina, da agricultura, da indústria bélica, automobilística dentre outras. Neste estudo como objetivo principal pretende-se destacar a in (existência) de regulamentação próprias para proteção dos trabalhadores, destacando sua vulnerabilidade frente ao desenvolvimento, causada por esta que é denominada a ciência do futuro: nanotecnologia. Como objetivos específicos, busca-se apontar os aspectos de segurança eficazes e suas contribuições para inserção no meio ambiente de trabalho para o tornar mais seguro, em respeito a dignidade do trabalhador, posto que são esses os mais vulneráveis no processo produtivo, diante da exposição às nanopartículas. Num cenário que os trabalhadores, sem a devida tutela do estado, sofrem as mazelas pela inercia na elaboração de normas próprias que o protejam.

Durante o desenvolvimento deste trabalho pretende-se ainda demonstrar as funções das normas protetivas trabalhistas que analogicamente em conjunto com o principio da proteção e da precaução, serão os balizadores em omissões em casos concretos. Desta forma pretendese apontar dentro das atividades realizadas no ambiente laboral, os aspectos legais do uso dessa nova tecnologia nas relações de trabalho destacando os vulneráveis e hipossuficientes trabalhadores que merecem uma maior proteção legal no seu ambiente de trabalho, tornandose vítimas em potencial, pela implantação destas novas tecnologias. O contato com substâncias nanocompostas, manipuladas no ambiente de trabalho, podem desencadear doenças futuras, possíveis riscos a saúde dos trabalhadores, o que os torna vulneráveis. E pela falta de normas protetivas que regulem o trabalho com a nanotecnologia, justifica o nosso estudo. A hipótese que a falta de conhecimento sobre essa nova área da ciência de diminutas grandezas e as incertezas geradas pelas descobertas científicas nanotecnológicas e suas aplicações, irá ter um grande impacto nas relações trabalhistas, onde nanotecnologia e ambiente de trabalho possam relacionar-se harmonicamente, remetem-nos a um outro campo que pensa de modo nada simplificador todos os processos envolvidos na nanotecnologia: o Pensamento Complexo Ecossistêmico e a Transdisciplinaridade.

\footnotetext{
${ }^{1}$ A nanotecnologia é a manipulação da matéria numa escala atômica e molecular. Geralmente lida com estruturas com medidas entre 1 a 100 nanômetros em ao menos uma dimensão, e incluí o desenvolvimento de materiais ou componentes e está associada a diversas áreas (como a medicina, eletrônica, ciência da computação, física, química, biologia e engenharia dos materiais) de pesquisa e produção na escala nano (escala atômica). O princípio básico da nanotecnologia é a construção de estruturas e novos materiais a partir dos átomos. É uma área promissora, mas que dá apenas seus primeiros passos, mostrando, contudo, resultados surpreendentes (na produção de semicondutores, Nanocompósitos, Biomateriais, Chips, entre outros).
} 
Assim, pensar de modo diferente os aspectos legais nas relações de trabalho e nos modos de produção, com o desenvolvimento de uma consciência mais humana, que respeite a dignidade e a integridade física dos vulneráveis no processo produtivo com nanotecnologia, é salutar e emergencial, tornando-se um dos objetivos de nosso estudo. De forma metodológica baseado em pesquisa bibliográfica e de forma comparativa com a legislação celetista existente, pretendem-se apontar a falta de normatização própria, os riscos que estão inseridos estes trabalhadores que manipulam ou estão em contato com nanocompósitos, trazendo um novo modo de pensar o Direito do Trabalho, um direito do trabalho digno em um mundo que avança rapidamente na produção científica e de novas tecnologias.

O estudo aborda que a convivência do trabalhador em seu ambiente de trabalho com uma vasta gama de compostos químicos (naturais ou sintetizados) é uma constante, desde a revolução industrial (séc. XVIII-XIX), intensificando o contato do trabalhador com novas substâncias e compostos químicos diversos, cada vez mais puros, complexos e com diferentes funções, e até mesmo desconhecidos seus efeitos colaterais pela própria ciência. Assim, a química orgânica mudou a indústria no século $\mathrm{XX}$, onde as combinações entre os átomos produziram novos materiais que levaram o Homem à Lua, às profundezas do mar, criaram drogas, remédios ou armas químicas. Foi em 29.12.1959, na reunião anual da Sociedade Americana de Física, que Richard Feynman ${ }^{2}$ apontou as oportunidades presentes nos materiais de dimensões próximas do nível atômico: os nano materiais.

As ocorrências de prováveis patologias oriundas das manipulações destes nanomateriais e a in(existência) de previsão legal de direitos que protejam o ser humano, sobretudo os trabalhadores vulneráveis, nessas evoluções científicas e tecnológicas justificam o tema e suas discussões: o direito à dignidade do ser humano e o princípio da precaução poderão contribuir para um novo modo de pensar essas questões, de forma complexa.

\footnotetext{
${ }^{2}$ Richard Philips Feynman foi um físico norte-americano do século XX, um dos pioneiros da eletrodinâmica quântica, e Nobel de Física de 1965. Adicionalmente a seus trabalhos sobre física teórica, Feynman foi pioneiro na área de computação quântica, introduzindo o conceito de nanotecnologia, no encontro anual da Sociedade Americana de Física, em 29 de dezembro de 1959, em sua palestra sobre o controle e manipulação da matéria em escala atômica.
} 


\section{2 - ASPECTOS DAS NANOTECNOLOGIAS: ALGUMAS OBSERVAÇÕES SOBRE QUESTÕES AMBIENTAIS, DE SAÚDE E SEGURANÇA DO TRABALHO}

A nanotecnologia opera em uma escala onde as estruturas e sistemas apresentam diferentes propriedades e funções em dimensões reduzidas (nanométricas). Dessa forma, é importante saber como que materiais na nanoescala interagem com o corpo humano e com o meio-ambiente, de modo que seja possível identificar e caracterizar potenciais exposições, determinar os possíveis impactos na saúde humana, bem como desenvolver métodos apropriados de controle e redução da exposição ao trabalhar com materiais na nanoescala.

Chen e Roco (2009, p.24) destacam que indústrias, agências governamentais especializadas, organizações civis e o público em geral rapidamente reconheceram os aspectos relacionados ao meio-ambiente, saúde e segurança dos trabalhadores ligados a áreas de nanotecnologias. Por conseguinte, sugerem que três aspectos imediatos e contínuos devem ser tratados simultaneamente ao desenvolvimento de produtos na nanoescala. Em primeiro lugar, destacam os autores Chen e Roco (2009, p.25) que laboratórios de pesquisa e unidades industriais devem entender as consequências das nanotecnologias para o meio-ambiente, saúde e segurança, e desenvolver medidas apropriadas de segurança para os trabalhadores. Exemplos de preocupações mais urgentes incluem a toxicidade das nanopartículas; mecanismos e rotas de exposição de nanoprodutos no ar, água e solo; eficácia de equipamentos de proteção pessoal como roupas especiais, respiradores, e controle de engenharia; comportamento das células na presença de nanoestruturas; e prevenção de liberação de nanopartículas sintéticas no meioambiente.

À medida que o conhecimento sobre os nanoprodutos se desenvolvem, as regulações já existentes sobre meio-ambiente de trabalho, saúde e segurança devem ser melhoradas e reforçadas. O segundo aspecto de acordo com Chen e Roco (2009, p.25) se refere à necessidade de padronização da linguagem dos pesquisadores das diferentes disciplinas e setores econômicos e industriais onde os trabalhadores estão inseridos e tendo contato com nanopartículas. Dessa forma, é necessário o desenvolvimento de nomenclaturas, normas, padrões e regulações internacionalmente aceitas de modo a apoiar o progresso da ciência, engenharia, tecnologia e novos mercados em nanotecnologias, sobretudo no meio ambiente de trabalho daqueles que se encontram em situação de vulnerabilidade. Exemplos desse tipo se referem ao desenvolvimento de instrumentação específica, sensores, e padrões para nanopartículas no ar, água e solo e no ambiente de trabalho.

Rev. de Direitos Fundamentais nas Relações do Trabalho, Sociais e Empresariais | e-ISSN: 2525-9903 | Porto Alegre | v. 4 | n. 2 | p. $83-105$ | Jul/Dez. 2018 
E não menos importante, em terceiro lugar Chen e Roco (2009, p.26) metodologias para análise de risco e governança devem ser desenvolvidas para a gestão de novos produtos e das tecnologias criadas no setor privado e governo, os autores ainda entendem que é importante destacar que o desenvolvimento da nanometrologia ${ }^{3}$ é fundamental neste contexto de prevenção da saúde do trabalhador exposto aos riscos de inalação e contaminação com nanopartículas. Sua aplicação sustenta toda a nanociência e nanotecnologia, uma vez que a habilidade para mensurar e caracterizar os materiais (determinar seu tamanho, forma, e propriedades físicas) na nanoescala é vital se os nanomateriais e dispositivos estão para ser produzidos a um alto grau de precisão e confiabilidade, e as aplicações da nanotecnologia estão para ser realizadas, além do grau de toxicidade.

Neste contexto, a dúvida que chama a atenção dos pesquisadores é a potencialidade dos riscos, pois seus efeitos na vida humana sobretudo dos trabalhadores ligados a cadeia produtiva de nanocompósitos, e no ecossistema, de maneira geral, são desconhecidos. O grande desafio lançado ao lado desta tecnologia são os seus riscos, e a partir disso devemos questionar a ausência de marcos regulatórios específicos, bem como a necessidade de refletir sobre respostas jurídicas que atendam às necessidades dos trabalhadores em seu meio ambiente de trabalho, dentro de um quadro de segurança humana e ambiental. (ENGELMANN, 2015, p. $15)$.

Assim, o mais instigante sobre os estudos das nanotecnologias e o meio ambiente de trabalho é que se desconhecem publicamente os possíveis riscos que elas podem gerar. Igualmente, nada ou pouco existe em termos de regulação jurídica da matéria. Não são solidamente conhecidas as propriedades físico-químicas, seu potencial de degradação e de acumulação no meio ambiente de trabalho e sua toxicidade ambiental, em relação ao trabalhador que tem contato direto na produção, dentre outros (HOHENDORFF, COIMBRA, ENGELMANN, 2016, 152).

Por estes motivos é que se faz imperiosa a discussão sobre o tema, a fim de pesquisar modelos regulatórios que resguardem o meio ambiente de trabalho em atenção ao primordial Princípio da Precaução ${ }^{4}$, que, neste caso específico, dita a observação de normas mínimas de

\footnotetext{
${ }^{3}$ A nanometrologia é um subcampo da metrologia, preocupado com a ciência da medição no nível da nanoescala. A nanometrologia tem um papel crucial na produção de nanomateriais e dispositivos com alto grau de precisão e confiabilidade na nanofabricação.

${ }^{4} \mathrm{O}$ princípio da precaução foi formulado pelos gregos e significa ter cuidado e estar ciente. Precaução relacionase com a associação respeitosa e funcional do homem com a natureza. Trata das ações antecipatórias para proteger a saúde das pessoas e dos ecossistemas. Precaução é um dos princípios que guia as atividades humanas e incorpora
} 
cuidado, funcionando, na verdade, não como uma diretriz teórica, mas como um guia de boas práticas, visto que a preocupação com o desenvolvimento desta nova tecnologia ultrapassa as fronteiras. Diante destes questionamentos, urge que se envolvam as mais variadas áreas de conhecimento, conforme citação de Engelmann:

Essa é a zona de discussão que está envolvendo estudiosos das mais variadas áreas de conhecimento. Sobre as descobertas já alcançadas em escala nano, cabe perguntar: qual é o limite dessa pesquisa em frações cada vez menores? Sabe-se, com a mesma precisão, quais as consequências dessa investida nano na natureza? Quando se estuda em escala nano, o que exatamente se tem como objeto? [...]. Essa escala de geração do conhecimento desafia a humanidade, pois é necessário obter dela efeitos práticos que possam alcançar benefícios aos humanos. Além disso, como novas possibilidades de conhecimento, antes de se festejar os avanços, torna-se imperioso analisar, com a maior precisão possível, as consequências e desdobramentos que serão provocados nos diversos espaços humanos (ENGELMANN; FLORES; WEYERMULLER, 2010, p 20).

Posto que ocorre a falta de consenso acerca da própria definição em diversas organizações internacionais - como a International Organization for Standardization (ISO), European Commission (EC), American Chemistry Council (ACC), German Chemical Industry Association (VCI), Food and Drug Administration (FDA-USA), o que representa mais uma comprovação da incerteza, da insegurança e do desconhecimento que perpassam as nanotecnologias, necessitando a prospecção regulatória focada na saúde e segurança do ser humano e do meio ambiente (ENGELMANN, 2014, p.339).

Diante da complexa diversidade de conceituação, o Brasil adotou o parâmetro de nanotecnologia da ISO TCC 229, observando-se a definição de nanomaterial da ISO/TR 128852008, sendo o nanomaterial engenheirado/manufaturado, ou seja, aquele intencionalmente produzido pelo homem, e/ou o que contém nano-objetos (ABDI, 2012, p7).

Como demonstrado, os aspectos nanotecnológicos e todas as preocupações apontadas convergem para um melhor entendimento e posteriormente para tomadas de decisões em ações que possam desencadear num ambiente laborativo seguro e apropriado para recepcionar as nanotecnologias em suas mais diversas formas de aplicação nas atividades empresariais, tirando o trabalhador da vulnerabilidade do desconhecido que se encontra atualmente, justificando o questionamento do próximo item deste estudo.

parte de outros conceitos como justiça, equidade, respeito, senso comum e prevenção. http://www.mma.gov.br/clima/protecao-da-camada-de-ozonio/item/7512 = acessado 05 ago 2018. 


\section{3 - AS NANOPARTICULAS, FORMAS DE CONTAMINAÇÃO E OS PERIGOS AOS TRABALHADORES VULNERÁVEIS}

Há pouca informação disponível sobre os riscos das nanopartículas em ambientes de trabalho, o Instituto Nacional de Saúde e Segurança Ocupacional (NIOSH) ${ }^{5}$ conduz uma pesquisa para determinar se elas acarretam um risco à saúde de trabalhadores expostos, onde demonstra que diferentes tipos de nanopartículas são feitas ou utilizadas em diversos processos industriais.

A partir destes questionamentos os envolvidos na pesquisa, em estudos laboratoriais em animais, mostraram que alguns tipos de nanopartículas quando inaladas podem atingir a corrente sanguínea, o cérebro e outros órgãos e têm mostrado efeitos adversos tais como inflamação e fibrose nos pulmões e outros órgãos. Justificada, portanto, a preocupação dos efeitos em Humanos, sobretudo aos trabalhadores que são a linha de frente da cadeia produtiva. Segundo os pesquisadores da NIOSH, não se encontram disponíveis no momento estudos sobre a exposição e resposta às nanopartículas absorvidas em humanos.

Tendo como finalidade a determinação se essas nanopartículas acarretam um risco aos trabalhadores, os cientistas devem avaliar e entender os seguintes aspectos: a) Quais os tipos e concentrações de nanopartículas no local de trabalho; b) Que propriedades das nanopartículas podem afetar o organismo humano; c) Quais os níveis de concentração de nanopartículas que podem produzir efeitos adversos.

A exposição ás nanopartículas se dá por três vias: inalação, ingestão e pela pele. A via mais comum de exposição é por inalação, mas a ingestão por transferência não intencional de materiais da mão para a boca ou ao ingerir partículas liberadas no trato respiratório, merece atenção, e por ultimo a através da pele, alguns estudos mencionam que as nanopartículas podem penetrar na pele. Essas possibilidades estão sendo investigadas, pois diversos fatores contribuem e afetam trabalhadores expostos às nanopartículas, sendo seus efeitos incertos, mas todas as exposições são afetadas pela concentração, duração e frequência, agravados os riscos ainda pela capacidade das nanopartículas em se dispersarem facilmente como poeira ou névoas (partículas líquidas) no ar podendo resultar em maior exposição ao trabalhador.

\footnotetext{
${ }^{5}$ NIOSH - National Institute for Occupational Safety and Health ou NIOSHI é a agência federal dos EUA responsável pela realização de pesquisas e produção de recomendações para a prevenção de lesões e doenças relacionada com o trabalho <https://pt.wikipedia.org/wiki/National_Institute_for_Occupational_Safety_and_Health>
} 
Neste cenário, é importante destacar a preocupação com incêndios e explosões, sendo um dos principais riscos associados com nanopartículas no local de trabalho. Alguns materiais na escala de nanômetro podem se tornar inexplicavelmente catalisadores químicos e resultar em reações inesperadas, expondo os trabalhadores a situações de periculosidade (embora não tendo norma positivada a tratar do tema).

Assim, como não foram estabelecidos padrões norte-americanos ou internacionais para nanopartículas. Embora mais pesquisas sejam necessárias, já se encontram disponíveis informações suficientes para fornecer recomendações provisórias e diretrizes sobre as exposições ocupacionais às nanopartículas. O NIOSH recomenda uma abordagem prudente para a fabricação e uso de nanopartículas na indústria, os empregadores devem tomar as medidas necessárias para minimizar a exposição de trabalhadores até que se tenham mais informações.

\section{4 - NORMAS DE DIREITO PROTETIVAS E SUAS FUNÇÕES}

As nanotecnologias inseridas no mercado de trabalho, conforme demonstrado em seus aspectos no item anterior, convergem para estabelecer uma possível relação de vulnerabilidade aos proletários que desconhecem e manipulam cada vez mais estes nano compósitos. Desta forma necessita-se demonstrar que o direito busca e tenta amoldar as normas protetivas à realidade do surgimento destas tecnologias no ambiente de trabalho, através da analise de suas funções.

Tendo como premissa de que as normas dos direitos protetivos, ao menos na lógica e na organização do sistema capitalista, não conseguem resolver os conflitos das inovações tecnológicas e suas implicações diretas causadas pelo contato dos trabalhadores com estas novas substancias, os colocando em vulnerabilidade, passamos a analisar as funções das normas sob o prisma de proteção na qual sua função pretende-se alcançar.

De forma simbólico-pedagógica, ressalvadas as hipóteses de regulação capturada ou ineficiente, as normas protetivas legais (ou mesmo regulatórias) podem induzir mudanças de comportamento; formas alternativas de controle social de fornecedores; rejeições coletivas a produtos e a serviços ofertados por determinada pessoa jurídica; reforço nos mecanismos 
de accountability ${ }^{6}$, alteração da cultura interna das empresas e perda do valor de mercado das corporações (DIAS TOFFOLI, 2012, p.56) .

Tanto maior a essencialidade dos produtos ou serviços, no entanto, tanto menor será o impacto dessa força simbólica e educativa das normas protetivas de trabalho, desta forma temos que o apelo pela necessidade de avanço tecnológico ultrapassa a necessidade de refrear sua evolução, porque poderia se cogitar que o trabalhador poderia encontrar-se vulnerável na manipulação e contato com substancias desconhecidas, se o progresso e o resultado da ciência para um todo fosse maior.

Em segundo a qual podemos dizer corretiva, é a mais (re)conhecida pelos agentes está na solução tópica, mesmo que não individual, de problemas gerados pela assimetria de posições técnicas (informações e conhecimento), econômicas e jurídicas entre trabalhadores e empregadores. O conhecimento e o estudo das normas de Direito do Trabalho, sobretudo aspectos implícitos do principio da proteção, também se prestam a ampliar o foco dessa segunda função, na medida em que permite o exame dos conflitos de maneira mais adequada e eficaz. Seu efeito está em milhares de sentenças proferidas que modificam ou declaram abusivas condições de ambiente de trabalho; reconhecem os direitos (legítimos) dos trabalhadores; adequam a prevenção do ambiente de trabalho em contato com produtos perigosos ou nocivos á saúde do trabalhador; asseguram a fruição de direitos e impedem as interrupções de outros tantos serviços necessários (DIAS TOFFOLI, 2012, p.58).

A grande vantagem desse reconhecimento dos limites do Direito, especialmente os morais diretamente ligado a dignidade do trabalhador, está em se deixar abertas as vias para o debate em fóruns democráticos não jurídicos. A vertigem desse novo poder, voltado para a defesa dos pobres e vulneráveis, trabalhadores frente a nanotecnologia fora ampliada pela cooperação dos doutrinadores e muitos professores de Direito, através de pesquisas e obras a tratar do tema, pois a vulnerabilidade e a hipossuficiência do trabalhador ainda perduram implícitas nos princípios e normas que regulam as relações de trabalho, sendo inevitável e

\footnotetext{
${ }^{6}$ Accountability é um termo da língua inglesa que pode ser traduzido para o português como responsabilidade com ética ${ }^{[1]} \mathrm{e}$ remete à obrigação, à transparência, de membros de um órgão administrativo ou representativo de prestar contas a instâncias controladoras ou a seus representados. Outro termo usado numa possível versão portuguesa é responsabilização. Também traduzida como prestação de contas, significa que quem desempenha funções de importância na sociedade deve regularmente explicar o que anda a fazer, como faz, por qual motivo faz, quanto gasta e o que vai fazer a seguir. Não se trata, portanto, apenas de prestar contas em termos quantitativos mas de auto-avaliar a obra feita, de dar a conhecer o que se conseguiu e de justificar aquilo em que se falhou. A obrigação de prestar contas, neste sentido amplo, é tanto maior quanto a função é publica, ou seja, quando se trata do desempenho de cargos pagos pelo dinheiro dos contribuintes.
} 
inquestionável o debate dos efeitos desta revolução nanotecnológica que passa a sociedade mundial, sobretudo o direito protetivo do hipossuficiente e vulnerável trabalhador frente às novas descobertas.

\section{5 - SAUDE, SEGURANÇA E NANOTECNOLOGIA NO DIREITO COLETIVO DO TRABALHO}

A saúde e a segurança do trabalhador vulnerável nunca estiveram tão em pauta. A legislação nacional, bem como as convenções e tratados internacionais, não acompanha as necessidades atuais dos trabalhadores no tocante à questão da saúde, da segurança no meio ambiente do trabalho e da sua dignidade, frente as nanotecnologias que invadem todas as atividades das cadeias produtivas, tornando-se imperioso seu debate e enfrentamento para melhor esclarecimento. As políticas públicas de prevenção de acidentes e a fiscalização não são compatíveis com o novo sistema, em que o mercado e os ganhos econômicos estão em primeiro lugar para os empresários. Estes não possuem mais a mesma preocupação em relação aos seus obreiros e não são capazes de vê-los como os responsáveis pelo seu sucesso; querem apenas lucro e mais lucro. (BARROS OLIVEIRA, 2000, p.37)

No contexto atual, a promoção da saúde como um todo é precária e alarmante. Neste cenário, as nanotecnologias avançam sobre os locais de trabalho, uma variedade de substancias novas, manipuladas em escalas nanométricas chegam nas cadeias produtivas de forma primaria ou secundária, sem o mínimo de informações necessárias para que estabeleça rotinas e meios de prevenção, precaução da saúde e segurança do trabalho, nestes atores vulneráveis que sempre serão os primeiros a terem contato com o novo. Além disso, o poder sindical uma das poucas esperanças dos trabalhadores, não possui mais imponência, sem representatividade, a força produtiva do país está entregue.

A defesa da utilização de equipamentos de proteção individual, em detrimento dos que poderiam significar a proteção coletiva; normatizam-se formas de trabalhar consideradas seguras, o que, em determinadas circunstâncias, supõe apenas um quadro de prevenção simbólica. Assumida essa perspectiva, são imputados aos trabalhadores os ônus por acidentes e doenças, concebidos como decorrentes da ignorância e da negligência, caracterizando uma dupla penalização (MACHADO; MINAYO-GOMEZ, 1995 apud MINAYO-GOMEZ; THEDIM-COSTA, 1997, p.34). 
Por outro lado, a essa forma inconsequente de lidar com a saúde e a vida, une-se a resistência dos indivíduos em aceitarem a condição de hipossuficientes, a pressão pela perda de emprego:

O medo de perder o emprego - garantia imediata de sobrevivência - aliado aos mais variados constrangimentos que marcam a trajetória do trabalhador doente, "afastado" do trabalho, mascara, em muitos casos, a percepção dos indícios de comprometimento da saúde ou desloca-os para outras esferas da vida, inibindo ou protelando, frequentemente, ações mais incisivas de reivindicação às instâncias responsáveis pela garantia da saúde no trabalho" (MINAYO-GOMEZ; THEDIM-COSTA, 1997, p 38).

Neste contexto, ficam vulneráveis os trabalhadores que desenvolvem suas atividades em nanotecnologias, pois o questionamento não lhes cabe, devem obedecer às ordens e executar suas tarefas impostas por um contrato de trabalho que não tem previsão de labor nanotecnológico nem o contato com nacompositos.

Uma estratégia adotada por empresários Europeus, a qual foi sugerida por um médico chamado Robert Becker, foi a de colocar em suas fábricas seus próprios médicos. Dessa forma, estes profissionais poderiam ter livre acesso às salas e aos ambientes de trabalho, com liberdade para terem conversas diretas com os trabalhadores, identificarem seus problemas e fazerem a intermediação entre os obreiros, seus patrões e os consumidores. Assim, após a identificação dos males que acometam o ambiente de labor, caberia aos médicos de cada empresa fazer cessar as causas dos danos, e tal responsabilidade se restringia apenas a este profissional, portanto, havendo doença relacionada ao ambiente de trabalho, era dever do médico extinguir seus efeitos, pois recairia sobre este a responsabilidade pelos danos causados por estas enfermidades. (MENDES; DIAS, 1991, p. 9).

O modelo proposto por Becker rapidamente se expandiu para o restante da Europa e, logo após, para os países periféricos.

\begin{abstract}
A inexistência ou a fragilidade dos sistemas de saúde, quer como expressão do seguro social, quer diretamente providos pelo Estado, via serviço de saúde pública, fez com que os serviços médicos de empresas passassem a exercer um papel vicariante, consolidando, ao mesmo tempo, sua vocação enquanto instrumento de criar e manter a dependência do trabalhador ao lado do exercício direto do controle da força de trabalho (MENDES; DIAS, 1991, p 25).
\end{abstract}

A crescente necessidade de fiscalização e de implementação de orientações em escala global culminou no nascimento da Organização Internacional do Trabalho (OIT) ${ }^{7}$, em 1919, havendo sido a primeira recomendação acerca de medicina do trabalho publicada no ano de

\footnotetext{
${ }^{7}$ Trata-se de uma agência multilateral da Organização das Nações Unidas, especializada nas questões do trabalho, especialmente no que se refere ao cumprimento das normas (convenções e recomendações) internacionais. Tem por missão promover oportunidades para que homens e mulheres possam ter acesso a um trabalho decente (conceito formalizado pela OIT em 1999) e produtivo, em condições de liberdade, equidade, segurança e dignidade humanas, sendo considerada condição fundamental para a superação da pobreza, a redução das desigualdades sociais, a garantia da governabilidade democrática e o desenvolvimento sustentável.
} 
1959, dispondo que a medicina do trabalho destina-se a: a) assegurar a proteção dos trabalhadores contra todo o risco que prejudique a sua saúde e que possa resultar de seu trabalho ou das condições em que este se efetue; b) contribuir à adaptação física e mental dos trabalhadores, em particular pela adequação do trabalho e pela sua colocação em lugares de trabalho correspondentes a suas aptidões; c) contribuir ao estabelecimento e manutenção do nível mais elevado possível do bem-estar físico e mental dos trabalhadores (VASCONCELLOS, 1995, p.15).

Com efeito, importante que se destaque, desde logo, a conotação e o respeito que se deu à questão da saúde mental do trabalhador. Vedou-se a exposição do trabalhador a agentes causadores de danos psíquicos, ambientes desumanos e degradantes, além de impor a necessidade de adequar o local de labor às condições e atribuições de cada obreiro, tratando-os de forma diferenciada e respeitosa, vez que estes são "objetos" ou "meios" de destaque na produção, na movimentação econômica e devem ter sua dignidade protegida de forma crucial.

Analisando, ainda, a questão da adequação do trabalhador ao ambiente e a importância dos cuidados a serem tomados com os obreiros, imperioso torna-se transcrever os comentários de Oliveira e Teixeira sobre o tema, no tocante aos seus resultados:

Em primeiro lugar, a seleção de pessoal possibilita a escolha de uma mão de obra menos geradora de problemas futuros como o absentismo e suas consequências (interrupção da produção, gastos com obrigações sociais, etc). Em segundo lugar, o controle deste absentismo na força de trabalho já empregada, analisando os casos de doenças, faltas, licenças, obviamente com mais cuidado e controle da empresa. Outro aspecto é a possibilidade de obter um retorno mais rápido da força de trabalho e produção. (OLIVEIRA; TEIXEIRA, 1986 apud MENDES; DIAS, 1991, 28).

No Brasil as discussões sobre a segurança e saúde do trabalhador acaloraram-se entre as décadas de 70 e 80, na chamada Revolução Sanitária Brasileira, que tinha como ideário a formulação de políticas públicas de saúde - um dos temas para a assembleia constituinte reformadora que seria realizada nos anos 80 . Nesse contexto, a cunhagem da expressão Saúde do Trabalhador foi se consolidando ao longo desses anos, principalmente a partir do discurso mais incisivamente reivindicatório e reformista do movimento sindical, mais combativo e sensível as questões da saúde, à base técnica e acadêmica das áreas que lidam com as relações saúde/segurança/trabalho (VASCONCELLOS, 1995, p.18).

Em 1986, a I Convenção Nacional de Saúde do Trabalhador apontou a necessidade da criação de políticas públicas que protegessem o obreiro de todos os males a ele expostos, incorporando tais responsabilidades ao Sistema Único de Saúde (SUS), constando em seu teor o Direito do trabalhador recusar-se a trabalhar em ambientes insalubres ou perigosos, recebendo normalmente seus salários enquanto não forem adotados, pelo empregador, todas as 
medidas tecnológicas disponíveis para eliminar ou diminuir a insalubridade e a periculosidade, nos limites de tolerância internacionalmente aceitos.

Desse modo, o trabalho nestes ambientes, garantidos o pagamento dos adicionais previstos em lei, seria acompanhado pelo sindicato da categoria. Desta forma inserida posteriormente na Constituição de 1988, no capítulo sobre a saúde, o que acarretou na evolução da legislação para as Normas Regulamentadoras, mas, contudo, deve sempre ser buscada pelo empregador a eliminação das nocividades e não somente compensação pela debilidade do seu sistema de produção por meio de acréscimo de salário, visto que a saúde e o bem estar do empregado não estão à venda.

\section{6 - OBSTÁCUlOS À PROTEÇÃO PLENA DO TRABALHADOR VULNERAVEL PELA IMPLANTAÇÃO DA NANOTECNOLOGIA NO AMBIENTE DE TRABALHO}

A linha econômica moderna impôs aos empregados uma série de ônus a suportar, uma vez que a legislação, bem como os meios de fiscalização, tornaram-se obsoletos em seus papeis fundamentais frente às nova exigências do mercado, como as novas nanotecnologias, que serão de acordo com os cientistas, o centro das atenções e dependências sociais nos anos futuros.

É certo que o Brasil é um dos países do mundo cuja legislação trabalhista é uma das mais completas, mas nem sempre a qualidade dos dispositivos significa o seu cumprimento, visto que sua eficácia está diretamente ligada aos meios de fiscalização eficientes, e, em sendo a norma celetista omissa no tocante aos trabalhos desenvolvidos em contato e manipulação nanotecnológica, imperiosa a atualização legislativa.

O Brasil, em particular, possui uma forte retaguarda normativa no tema da segurança e saúde no trabalho e o mesmo não se dá nos demais países [do Mercosul]. Cabe destacar que a extensa normatização brasileira pode ser 'confundida' com um excesso de regulamentação governamental nas questões privadas e entrar no bojo das propostas flexibilizadoras do neoliberalismo. (RIBEIRO, 1997 apud OLIVEIRA; VASCONCELLOS, 2000, p.39).

Portanto, apesar de incontáveis normas protetivas, a tal proteção que se espera não é o que se vê na prática. A todo o momento vemos trabalhadores tendo seus direitos lesados e nunca houve tantos acidentes e doenças do trabalho como hoje. Nos últimos vinte anos, considerandose apenas os casos ocorridos no Brasil com trabalhadores segurados pela Previdência Social, houve mais de meio milhão de mortes ou incapacidades permanentes para o trabalho. No total, considerando-se os acidentes de trabalho oficialmente notificados (com a emissão da CAT), sem considerar os trabalhadores acidentados, que não são contratados pela Consolidação das 
Leis do Trabalho, e apesar de conhecida subnotificação dos acidentes, nos últimos 20 anos ocorreram em torno de trinta milhões de eventos (POSSAS, 1989; MACHADO, 1991 apud OLIVEIRA; VASCONCELLOS, 2000, p.45).

Frise-se que grande parte da culpa deverá recair sobre os empregadores, pois são nestes meios que o trabalhador é visto apenas como objeto de produção. A necessidade de avançar para almejar conquistas cada vez mais lucrativas acaba "vendando" os olhos do empregador no que concerne ao carro chefe do seu sucesso: o empregado (DRUCK; FRANCO, 1997, p. 18).

O crescimento desenfreado da economia e tecnologia geram uma concentração de esforços do empresário apenas no trabalho do obreiro e em sua produção, tornando os empreendedores omissos no que se refere às medidas preventivas de acidentes e de doenças laborais, frente a novas descobertas e novos produtos inseridos no mercado de trabalho, como se destaca as nanotecnologias.

Admite, Vasconcellos (1995, p 21), que o discurso corrente da qualidade total é voltado invariavelmente para a qualidade do produto, sem levar em conta a qualidade de vida do produtor do produto, ou seja, o trabalhador. A conquista de novos mercados é a meta primordial das empresas e apesar de haver algum ganho do consumidor, o trabalhador não é incorporado como alvo do sistema gestor de qualidade, mas sim um vulnerável.

Outro entrave reside no fato de a emissão da Comunicação de Acidente de Trabalho (CAT) ser de responsabilidade dos empregadores. É sabido que muitas empresas ainda resistem em atender à legislação e emitir este comunicado e, muitas vezes, só o fazem quando os agravos à saúde já são irreparáveis e o trabalhador já é considerado incapaz para o trabalho e insuscetível de reabilitação para o exercício de qualquer atividade (MIRANDA, 2006, p.34),, o que torna mais difícil o levantamento de dados reais, sobretudo os relacionados a acidentes com produtos nanotecnológicos.

A preferência dos empregadores por não lançar a CAT acaba por prejudicar os trabalhadores como um todo, eis que os dados do INSS sobre acidentes de trabalho passam a serem desatualizados e precários de informações, e, quando se omite a ocorrência de uma doença laboral, não há como o Estado interferir na questão preventiva específica, o que poderia contribuir para realização de um rastreamento de patologias oriundas da exposição com nanocompósitos.

Ademais, o sistema público de saúde (SUS) é falido e a previdência está abarrotada de beneficiários esvaziando seus cofres. Sendo assim, os trabalhadores tornam-se reféns 
vulneráveis, pois concentram todos os seus esforços no sentido do ganho econômico e se sujeitam às condições insalubres sem questionar que tipos de nacompositos manipulam ou estejam expostos, e ainda sem a regulamentação de receber o devido adicional por esta condição insalubre ou perigosa. Deste modo, observa-se que quem assume a conta e os riscos são aqueles que deveriam estar plenamente protegidos.

Apesar das mudanças estabelecidas na legislação trabalhista, foram mantidas na legislação previdenciária/acidentária as características básicas de uma prática medicalizada, de cunho individual, e voltada exclusivamente para os trabalhadores engajados no setor formal de trabalho. Caberia saber porque o modelo da saúde ocupacional não conseguiu atingir os objetivos propostos. Dentre os fatores que poderiam ser listados estão: a) o modelo mantém o referencial da medicina do trabalho firmado no mecanicismo; b) não concretiza o apelo à interdisciplinaridade: as atividades apenas se justapõem de maneira desarticulada e são dificultadas pelas lutas corporativas; c) a capacitação de recursos humanos, a produção de conhecimento e tecnologia de intervenção não acompanham o ritmo da transformação dos processos de trabalho; d) o modelo, apesar de enfocar a questão do coletivo de trabalhadores, continua a abordá-los como "objeto" das ações de saúde; d) a manutenção da saúde ocupacional no âmbito do trabalho, em detrimento do setor saúde. (MENDES; DIAS, 1991, p 27).

Com efeito, o Estado não tem se atentado que a grande problemática da relação trabalho-saúde está sob o seu poder. O modelo de prevenção concentra-se no trabalhador como o "objeto das ações de saúde", quando o entrave está numa questão muito mais abrangente e geral: a saúde como um todo. Quando as políticas públicas voltadas à promoção da saúde não estão em ordem, não há como existirem ações específicas eficazes.

Um outro problema, neste mesmo sentido, se encontra na desorganização dos entes fiscalizadores. Como é comum em nosso país, a delegação de funções e a quantidade de organismos são imensas, o que torna a fiscalização praticamente sem efeito.

\begin{abstract}
Alguns órgãos atuam na prevenção, outros nas consequências e outros ainda na reparação, mas ninguém tem visão nítida do conjunto. $\mathrm{O}$ fracionamento dessas competências faz com que o grande problema da saúde do trabalhador seja transformado numa questão menor, diluída no quadro de atribuições de cada um desses órgãos. (OLIVEIRA, 1996, p 28).
\end{abstract}

Nesse passo, fica compreensível porque é tão difícil diagnosticar e tratar uma doença do trabalho: a passagem por processos produtivos diversos podem mascarar os nexos causais e diluir a possibilidade de estabelecê-los (MINAYO-GOMEZ; THEDIM-COSTA, 1997, p 41). Vasconcellos e Oliveira defendem:

A criação de um "Sistema Integral de Saúde do Trabalhador", configurado em rede e subordinado ao setor de saúde, mas que passe, necessariamente, pelas instâncias do Estado e sociedade. Ora, o que os eminentes autores sugerem é que haja, além de um órgão ou um ministério centralizado e específico, uma maior participação da sociedade, do Estado, dos entes sindicais, dos setores com responsabilidade no campo 
ambiental, para que se reordene a produção de conhecimentos nos campos pragmáticos da saúde do trabalhador ( OLIVEIRA; VASCONCELLOS, 2000, p.39).

Políticas como essa permitirão que o obreiro se sinta valorizado, seguro, abraçado pela lei e pelas ações de governo nesse sentido. Outro modo de elevar a estima do empregado, e forçar o cumprimento das ações preventivas pelo empregador, é a criação de um certificado de qualidade de vida no trabalho, como sugerem os autores (OLIVEIRA; VASCONCELLOS, 2000, p.42).

Para terem direito ao certificado, os empreendedores deveriam cumprir determinadas metas, dentre elas possuírem um sistema de controle de riscos para os trabalhadores envolvidos em nanotecnologia. Assim, receberiam incentivos fiscais, o que engrandeceria ainda mais os cuidados a serem tomados.

Voltando-se a atenção governamental para a questão do meio ambiente do trabalho, muito mais protegidos estarão os trabalhadores, pois, em tese, as forças estarão direcionadas para a prevenção, tornando digno e adequado o local de labor, reduzindo, assim, a probabilidade de ocorrências de doenças ou acidentes de trabalho, envolvendo as nanotecnologias. Nos dizeres de Raimundo Simão de Melo:

\begin{abstract}
O meio ambiente de trabalho é o local onde as pessoas desempenham suas atividades laborais, sejam remuneradas ou não, cujo equilíbrio está baseado na salubridade do meio e na ausência de agentes que comprometam a incolumidade físico-psíquica dos trabalhadores, independentemente da condição que ostentam (homens ou mulheres, maiores ou menores de idade, celetistas, servidores públicos, autônomos, etc) (...) O meio ambiente de trabalho adequado e seguro é um dos mais importantes e fundamentais direitos do cidadão trabalhador, o qual, se desrespeitado, provoca agressão a toda a sociedade, que, no final das contas, é quem custeia a Previdência Social. (DE MELO, 2011, p.5).
\end{abstract}

O direito a um meio ambiente seguro é cláusula intrínseca ao contrato de trabalho, não necessitando ser expressa, pois é condição inerente à atividade e, inclusive, propiciadora de melhor aproveitamento do trabalhador na própria produção, beneficiando até mesmo seu empregador. Portanto, permitir ou forçar o obreiro a trabalhar em ambiente inadequado sem informações das nanotecnologias envolvidas, torna-se uma verdadeira afronta aos mais básicos princípios inerentes à raça humana: atinge de forma visceral o plano da dignidade e da honra do trabalhador, expondo-os aos meios que poderão torná-lo provisoriamente doente, incapaz ou até mesmo, em casos extremos, tirando-lhes a vida.

Assim, percebe-se que os trabalhadores não estão completamente protegidos. Os obstáculos são grandes e numerosos, discussões via judiciais e decisões sobre o tema já existem. A previsão em normas coletivas trabalhistas com cláusulas de uso da nanotecnologia no ambiente de trabalho de determinadas classes, como citamos a exemplo o dissidio coletivo na 
qual em decisão pela Justiça do Trabalho do TRT $15^{\text {a }}$ Região, a relatora em análise as cláusulas da norma coletiva, deferiu e julgou procedente a manutenção da cláusula $101^{\mathrm{a}}$ da NANOTECNOLOGIA, argumentando que a mesma é necessária em razão do principio do protecionismo, da precaução e por se tratar de cláusula que envolve a higidez, segurança e saúde dos trabalhadores que podem estar vulneráveis frente a nanotecnologia:

PROCESSO no 0006151-86.2013.5.15.0000 (DC) - DISSÍDIOCOLETIVO DE
NATUREZA ECONÔMICA SUSCITANTE: SINDICATO DOS
TRABALHADORES NAS INDÚSTRIAS DA FABRICACAO DO ÁLCOOL,
ETANOL, BIOETANOL, BIOCOMBUSTIVEL, QUIMICAS E E
FARMACEUTICAS DE RIBEIRAO PRETO E RE: SUSCITADO : BIOSEV
BIOENERGIA S.A. RELATORA: ADRIENE SIDNEI DE MOURA DAVID
DIAMANTINO Relatório Trata-se de Dissídio Coletivo de natureza econômica e
social, instaurado pelo SINDICATO DOS TRABALHADORES NAS
INDÚSTRIAS DA FABRICAÇÃO DO ÁLCOOL, ETANOL, BIOETANOL,
BIOCOMBUSTÍVEL, QUÍMICAS E FARMACÊUTICAS DE RIBEIRÃO PRETO
E REGIÃO, (...) com o objetivo de estabelecer a fixação de cláusulas econômicas e
sociais, a partir de 01 de maio de 2013, para a categoria profissional por ele
representada. CLÁUSULA 101 ${ }^{2}$ - NANOTECNOLOGIA Reivindicação: As
empresas são obrigadas a informar a entidade sindical sobre o uso de nanotecnologia
no processo industrial e no ambiente de trabalho. No uso de nanotecnologia serão
tomadas as devidas providencias de proteção e monitoramento da saúde dos
trabalhadores. Iniciar processo de informação ampla sobre os conceitos básicos de
nanotecnologias: o que é, a importância, os possíveis usos e as incertezas; (....)
Defiro. Redação final da cláusula: Não alterada (http://portal.trt15.jus.br/consulta-
processual, acessado em 04 ago 2018).

No referido julgado restou clara a intenção normativa em proporcionar a comunicação clara aos empregados da utilização de nanotecnologia no processo produtivo, para que seja esta comunicação um meio de alerta aos empregados sobre riscos dos quais estão sujeitos para que os próprios empregados possam ter o conhecimento necessário para a promoção da segurança no local de trabalho, procedimentos de verificação de vazamentos, primeiros socorros e estratégias de prevenção e monitoramento da saúde do próprio empregado. Desse modo, a empresa que optar pela utilização de nanotecnologia deve ter como norte os Princípios da Precaução e da Proteção, adotando medidas preventivas que se não evitem, minimizem os danos em uma eventualidade casuística de sinistro laboral.

Apesar de tímidas ainda as discussões por falta de legislação e possíveis casos não comprovados ainda de infecções e patologias que possuem nexo causal com o contato de nanotecnologias, já se admite em normas coletivas e decisões de tribunais trabalhistas que o empregador deve informar aos trabalhadores quais substancias que os mesmos estão manipulando ou tendo contato, conforme podemos notar no exemplo dado acima, o que poderá ocorrer no futuro de uma consolidação de temas neste aspecto. 
A CLT prevê no seu conteúdo o pagamento de adicionais aos trabalhadores sujeitos a condições insalubres e perigosas, bem delineadas e já definidas no próprio texto da norma trabalhista, contudo, ainda mesmo após a reforma trabalhista ocorrida na lei 13.467/2017, em vigor a partir de novembro de 2017, a omissão na norma ainda persiste. Não há menção no texto legal da previsibilidade de contato/exposição de trabalhadores a nanocompósitos. Na falta de legislação especifica, e da inercia da tutela do Estado em não regular ou legislar sobre o contato do trabalhador com estas nanotecnologias e os possíveis agravamentos patológicos destas atividades, deixando o trabalhador vulnerável ao acaso do desconhecido, sem mesmo ganhar um devido adicional a sua remuneração pela exposição, se faz necessário os magistrados analogicamente aplicarem as legislações existentes de acordo com os casos concretos.

Um paradigma sem solução, pois a manipulação ou contato com nanocompósitos, analogicamente enquadraria nas previsões dos artigos 189 e 193 da CLT. De forma especifica a insalubridade segundo a norma legal citada, pode ser cessada se houver a neutralização ou redução dos componentes que contribuem para o ambiente insalubre em níveis aceitáveis pelas leis de medicina e segurança do trabalho. O trabalho em exposição à substancias nanotecnológicas, seria considerado condição insalubre ou perigosa?

Este questionamento necessita de um aprofundamento na interpretação das leis de proteção do trabalhador no ambiente de trabalho, e ainda no principio da precaução. Em razão da inexistência de norma positivada tratando da questão do ambiente de trabalho que envolve o contato e manipulação de nanocompósitos, nenhuma obrigação impõe-se ao empregador para que de uma forma ou de outra, passe a pagar o devido adicional, agravando ainda mais em caso de patologias oriundas da relação de trabalho, também denominadas de doença ocupacionais.

Mesmo que a norma celetista não mencione a nanotecnologia como uma das causas de direito ao devido adicional (periculosidade ou insalubridade), há que se aplicar as normas existentes, na singela interpretação dos princípios do protecionismo e da precaução, que são elementos intrínsecos quando falamos de hipossuficientes, no caso em estudo o trabalhador que é vulnerável em contato com tecnologias e nanocompósitos desconhecidos.

Conforme assevera Góes, as negociações coletivas são um meio de regulação não tradicional, onde se impõe aos sindicatos - até por força de Lei (art. $8^{\circ}$ da Consolidação das Leis do Trabalho - a prerrogativa de iniciarem, entabularem e promoverem estas tratativas para promoção do dialogo entre as categorias profissionais e econômicas, onde por meio da autocomposição der conflitos, enseje que as categorias se autorregulem (GOES, 2015,p.137). 
Desta forma, ao empresário revela-se um tanto promissor, porém não podemos afirmar o mesmo em relação aos seus trabalhadores, diante da precarização dos direitos trabalhistas e enfraquecimentos dos sindicatos.

Assim, o Empregado, cercado de potenciais agentes agressores durante todo o período de trabalho, sofre com a falta de normas próprias para tutelar seus direitos de um ambiente laborativo seguro, especialmente quando a atividade utiliza nanocompósitos, tornando-o ainda mais vulnerável.

\section{7 - CONCLUSAO}

As nanotecnologias têm aberto oportunidades para o desenvolvimento de novos produtos com propriedades, funcionalidades e características distintas e muitas vezes superiores aos materiais usuais. Estas características podem ser utilizadas no desenvolvimento de materiais nanocompósitos nos mais diversos ramos da economia, considerada pelos cientistas a ciência do futuro, que predominará e fará parte da dependência humana por tecnologia. Porém, a síntese, estocagem, manuseio, estabilização, incorporação dos nanomateriais traz também desafios e a necessidade uma análise profunda dos processos, adequações de procedimentos operacionais e das instalações industriais em decorrência de novos riscos envolvidos os trabalhadores e colocando-os em condições de vulnerabilidade quando da utilização destes materiais nanoparticulados.

Contudo, como tratado neste estudo, o amparo ao trabalhador exige muito mais que uma série de leis específicas ou a criação de inúmeros órgãos governamentais de fiscalização, necessita-se de empenho, dedicação exclusiva para que se tenha eficácia, na criação de normas que atendam as atividades a serem desenvolvidas sob a égide nanotecnológica. Não é razoável que se proteja o trabalhador vulnerável frente ás nanotecnologias com apenas uma caneta e papel.

O estudo confirma a hipótese inicial e a importância do tema no sentido que as legislações (in)existentes não conseguem regulamentar as condições deste tipo de trabalho e suas nuances operacionais no contato do trabalhador com nanomateriais. Um ambiente de trabalho seguro e nanotecnologia podem conviver, mas são necessários projetos, discussões e audiências públicas, porque o problema tema deste estudo e enfatizado é de ordem social, e não uma questão particular de cada empregado, Imperioso a adequação dos equipamentos de proteção individuais especiais (luvas, roupas protetoras, respiradores, etc.), o uso correto de 
equipamentos de proteção coletiva e individual, os quais sempre devem fazer parte de um programa global de proteção e saúde do trabalhador em conjunto com as recomendações e exigências legais de proteção da saúde e segurança do trabalhador tais como a NR-7 (PCMSO - Programa de Controle Médico de Saúde Ocupacional) e NR-9 (PPRA - Programa de Prevenção de Riscos Ambientais).

Conclui-se que alguns dos maiores desafios para o desenvolvimento seguro da nanotecnologia e um ambiente de trabalho seguro face a in(existência) de normas, deve-se a estratégia de gestão da análise de decisão aplicada à nanopartículas manipuladas no ambiente de trabalho, as quais seriam de forma conclusiva: a) Riscos durante o processo de armazenamento e manuseio dos nano materiais, as etapas de armazenamento e manuseio são críticas na utilização de nano materiais, uma vez que, é neste momento que ocorre o primeiro contato entre os trabalhadores e os nano materiais. b) Risco de incêndio e explosão, o risco de incêndio e explosão das atividades de manuseio é inerente quando se trabalha com materiais com alta energia armazenada. No caso de nano matérias, a diminuição do tamanho das partículas aumenta consideravelmente a energia superficial (e total) do sistema particulado. Em meio a tantos riscos à saúde do trabalhador que podem ser ocasionados pelo uso das nanotecnologias, o conhecimento prévio e o princípio da precaução dentro da gestão de saúde e segurança ocupacional devem ser ponderados para garantir à sua saúde, bem estar e dignidade ao trabalhador. Por ser complexo o desenvolvimento da nanotecnologia, os produtos e processos inovadores eventualmente baseados em nanopartículas não constituem garantia ou mesmo condição suficiente para o desenvolvimento e melhoria da qualidade de vida dos trabalhadores, até mesmo pela falta de EPIS adequados especificamente para protegê-los. Somente quando acompanhada por mudanças nas relações sociais, econômicas e culturais, e após debate político garantidor do Direito das pessoas, com medidas regulatórias e fiscalizadoras para evitar danos à saúde do trabalhador as novas tecnologias poderão trazer bem-estar e conviver em harmonia no ambiente de trabalho.

Dessa forma, algo transcendental como as potencialidades da implementação da nanotecnologia em um ambiente de trabalho seguro, somente serão alcançados como apontado no desenvolvimento as hipóteses e objetivos específicos deste estudo, através da busca de uma correta identificação destes nanomateriais, caracterização, determinação das rotas e mecanismos de exposição, avaliação e gestão dos riscos envolvidos, indicação de equipamentos de proteção coletiva e individual específicos, aplicação de leis análogas como os artigos 189 e 193 da CLT, pontos determinantes para a garantia da saúde e integridade física dos 
trabalhadores, além da manutenção do meio ambiente, que pela promoção da ostensiva informação e capacitação dos trabalhadores possibilite aos mesmos terem uma atitude segura frente aos riscos que correm no local de trabalho, garantindo desta forma uma convivência pacífica entre os nanomateriais e um meio ambiente laborativo seguro.

\section{8 - REFERENCIAS}

ABDI - Agência Brasileira de Desenvolvimento Industrial. Relatório de Acompanhamento Setorial. Nanotecnologia na área da saúde: mercado, segurança e regulação. Jan. 2013. Disponível em: < http://www.abdi.com.br/Estudo/relatorio-nanotecnologia.pdf > Acesso em: 05 ago. 2018.

BARROS OLIVEIRA, Maria Helena; FADEL DE VASCONCELLOS, Luiz Carlos. As políticas públicas brasileiras de saúdo do trabalhador. Tempos de avaliação. 2000.

BERGER FILHO, A. G., Nanotecnologia e o princípio da precaução na sociedade de risco. Âmbito Jurídico. 2010. Disponível em: <http://www.ambitojuridico.com.br/site/index.php?n_link=revista_artigos_leitura\&artigo_id=7084>. Acesso em: 05 ago. 2018.

BIBLIOTECA: http:// biblioteca.planejamento.gov.br/biblioteca-tematica-1/textos/trabalho-eprevidencia/texto-37-2013-as-politicas-publicas-brasileiras-sobre-a-saude-do-trabalhador.pdf. Acessado em 25 Jul 2018.

CHEN, H. \& ROCO, M.C "Nanotechnology: An Emerging Field”, In: CHEN, H. \& ROCO, M.C., "Mapping Nanotechnology Innovations and Knowledge - Global Longitudinal Patent and Literature Analysis". Integrated Series in Information Systems. Springer. . (2009). ConvençãoNacionaldeSaúdedoTrabalhadorhttp://bvsms.saude.gov.br/bvs/publicacoes/1a_con f_nac_saude trabalhador.pdf, acessado em 02 ago 2018.

DE MELO, Raimundo Simão. Direito Ambiental do Trabalho e Saúde do Trabalhador. $3^{\mathrm{a}}$ Edição - LTR. São Paulo 2011.

DIAS TOFFOLI, José Antonio Dias. O CNJ tira poderes das elites estaduais. Entrevista por Eumano Silva e Leonel Rocha. Revista Época, edição 712, p. 56-58, 9/1/2012.

DREXLER, K. ERIC. Engines of creation: the coming era of nanotechnology. New York/USA: Anchor Books, 1986 pp. 298.

DRUCK, G.; FRANCO, T. - A Degradação do Trabalho e os Riscos Industriais no Contexto da Globalização, Reestruturação Produtiva e das Políticas Neoliberais. In: FRANCO, T. (org.). Trabalho, Riscos Ambientais e Meio Ambiente: Rumo ao Desenvolvimento Sustentável?. Salvador, Ed. EDUFBA, 1997. p. 15-32.

EBAH - http://www.ebah.com.br/content/ABAAAA7yIAB/nanotecnologia-impactos-a-saudehumana?part=5 - acessado em 04 ago 2.018). 
FADEL DE VASCONCELlOS, L. C.,. Saúde no Mundo do Trabalho - Perspectivas para o Brasil do $3^{\circ}$ milênio, in América Latina e Caribe, Desafios do Século XXI, Rio de Janeiro: Programa de Estudos de América Latina e Caribe (PROEALC) / Centro de Ciências Sociais da Universidade do Estado do Rio de Janeiro, 1995.

GÓES, Mauricio de Carvalho. Direito das nanotecnologias e o meio ambiente de trabalho. Porto Alegre: Livraria do Advogado, 2015. p. 137.

ENGELMANN, Wilson; FLORES, André Stringhi; WEYERMÜLLER, André Rafael. Nanotecnologias, marcos regulatórios e direito ambiental: construindo um diálogo transdisciplinar na busca de marcos regulatórios em nanotecnologias. 1. ed. Curitiba: Honoris Causa, 2010.

ENGELMANN, Wilson; HOHENDORFF, Raquel Von; FROHLICH, Afonso. Das nanotecnologias aos nanocosméticos: conhecendo as novidades na escala manométrica. In: ENGELMANN, Wilson. Nanocosméticos e o Direito à Informação. Erechim: Devian, 2015. Pg. 15-76.

ENGELMANN, Wilson. As nanotecnologias como um fator de aproximação democrática dos países da América Latina: em busca de moldes regulatórios. In: ENGELMANN, Wilson; SPRICIGO, Carlos M. (orgs.) Constitucionalismo democrático na América Latina: desafios do século XXI. Curitiba: Multideia, 2015. p. 105-122.

HOHENDORFF, Raquel Von; COIMBRA, Rodrigo; ENGELMANN, Wilson. As nanotecnologias, os riscos e as interfaces com o direito à saúde do trabalhador. RIL. Brasília. a.53. n. 209. p.151 - 172.jan./mar.2016.

MENDES, R. \& DIAS, E.C. [From occupational medicine to workers' health]. Rev. Saúde públ, S. Paulo, 25: 341-9, 1991

MENDES, René; DIAS, Elizabeth Costa. Da medicina do trabalho à saúde do trabalhador. 1991. Disponível em http://www.scielo.br/pdf/rsp/v25n5/03.pdf. Acessado em 05/08/2018.

MINAYO GOMEZ, Carlos; THEDIM-COSTA, S. M da Fonseca. A construção do campo da saúde do trabalhador: percurso e dilemas. Cadernos de saúde pública, 1997. Disponível em http://www.ambitojuridico.com.br/site/index.php/\%3Fn_link\%3Drevista_artigos_leitura\%26a rtigo_id\%3D12559\%26revista_caderno\%3D28?n_link=revista_artigos_leitura\&artigo_id=16 $441 \&$ revista_caderno $=25$ - acessado em 28 jul 2018.

MIRANDA, Carlos Roberto. Ataque ao mundo do trabalho: terceirização e seus reflexos na segurança e saúde do trabalhador. 2006. Portal Saúde e Trabalho Online. Disponível em www.saudeetrabalho.com.br. Acessado em 05 ago 2018.

MORAES, M. C. Ecologia dos saberes: complexidade, transdisciplinaridade e educação: novos fundamentos para iluminar novas práticas educacionais. São Paulo: Antakarana/WHH - Willis Harman House, 2008.

NIOSH - https://www.cdc.gov/niosh/topics/nanotech/nanotechnology-research-center.html acessado em 05 ago 2018). 
ROCO, M. C. (2011). The Long View of Nanotechnology Development: The National Nanotechnology Initiative at Ten Years. Nanotechnology Research Directions for Societal Needs in 2020. Science Policy Reports, Vol. 1, pp. 1-28.

TRT 15 Região, Processo no 0006151-86.2013.5.15.0000 (DC) - Dissidio Coletivo de Natureza Econômica: http://portal.trt15.jus.br/consulta-processual, acessado em 04 ago 2018). 